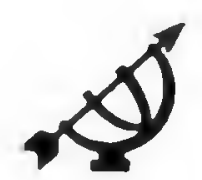

\title{
Ontological considerations in the study of Logic
}

\author{
D.F.M. Strauss \\ Dean: Faculty of Humanities \\ University of the Free State \\ BLOEMFONTEIN \\ E-mail: fgds@rs uovs.ac.za
}

\begin{abstract}
Ontological considerations in the study of Logic

Studying logical thinking requires a more than logical diversity within creation. As a consequence, an answer has to be given to the issue regarding the cohering diversity given in reality. All monistic-isms should be seen as attempts to give a negative answer to this question. The legacy of Reformational philosophy, however, does make it possible to address these issues with the aid of its theory of inter-modal coherences. This theory is articulated in terms of retrocipatory and anticipatory moments of coherence (called analogies). It enables one to come up with an evaluation evincing both a sense of critique and a sense of solidarity with what is called - in certain contexts of the philosophy of science - "epistemic values". In addition it provides one with a method to analyze the nature and scope of fundamental logical principles - viewed as modal analogies which at the lawside of the analytical aspect of reality refer to other aspects of reality. In particular - against the background of certain starting points in Greek thought - a closer account is given of the controversial status of the principle of the excluded middle. In conclusion - with reference to particular examples - attention is given to various ways of exercising critique.
\end{abstract}

\section{Introductory remarks}

In this article we proceed from the assumption that the ability to conceptualize, judge and argue presupposes the logical-analytical aspect of reality. It is the task of logic to use this facet of reality as its point of entry in analysing the rules governing (formal or informal) valid logical reasoning. These rules pre-suppose universal modal logical principles which are themselves dependent upon an inter-modal principle, namely that of the excluded antinomy. 
The structure of the logical aspect evinces its meaning only in coherence with all the non-logical aspects of creation. This inter-modal coherence accounts for the unavoidability of using elementary basic concepts reflecting this inter-modal coherence. The methodological implication of this starting-point provides us with a new insight into the nature of logical principles, such as the principle of identity (principium identitatis), the principle of contradiction (principium contradictionis), the principle of the exluded middle (exlusii tertii) and the principle of sufficient reason (principium rationis sufficientis). Different forms of criticism should be accounted for - such as immanent criticism, transcendent criticism, and transcendental criticism.

\section{Continuity and discontinuity}

In the contemporary philosophy of science there seemingly exists a tension between Kuhn's emphasis on scientific revolutions and Holton's pre-occupation with persistent themes. Although one may view the rise of Reformational philosophy, in the Kuhnian sense of the word, as a scientific revolution, one is equally justified in claiming that this new philosophical perspective developed by giving an answer to basic issues in philosophy showing continuity with the rich philosophical legacy of the West.

In order to show that an analysis of the place and structure of the logical aspect, as well as an account of the nature of logical principles, is dependent upon fundamental philosophical issues, we start by introducing some crucial distinctions while dealing with the classical philosophical issue of the "coherence of irreducibles".

\section{The "coherence of irreducibles"}

Perhaps one can claim that one of the most basic of all philosophical problems concerns this issue of the "coherence of irreducibles". One may consider all monistic approaches in philosophy and the special sciences as implicitly answering this question in the negative. Monistic pan-psychism (for example the views of Theilhard de Chardin), wants to reduce every phenomenon to a psychic perspective. In a similar way, the classical mechanistic approach in physics, following Galileo's discovery of the kinematical law of inertia, has tried, at least in its main trend, to view all physical bodies exclusively in terms of mechanical movement. 1 However, Planck's discovery of the quantum and the establishment of the second main law of thermodynamics, i.e. the law of non-decreasing entropy

1 The most comprehensive, but perhaps last attempt to reduce all physical phenomena to kinematical movement, is found in the mechanics of $\mathrm{H}$. Hertz - he was the first to broadcast and receive radio waves and established that light and heat are eletromagnetic waves. 
(indicating the irreversibility of physical processes), revealed the untenability of this monistic mechanistic approach in modern physics.

What is normally referred to as "primitives" in logic and in foundational studies, indeed pertain to the "irreducibles" mentioned above. These primitives also reflect the inherent limitations of concept-formation and definition - in the final analysis every definition can only define something in indefinable terms. Whenever one tries to define a truly primitive notion, the inevitable result is circularity or (antinomıc) reduction.

Zeno's classical reasoning against the reality of movement is nothing but an attempt to define pure movement, a primitive notion in kinematics, solely in static spattal terms - as if a moving body possesses from moment to moment a definite place in space. In his fourth fragment one reads: "something in motion neither moves in the space it is occupying, nor in the space it does not occupy" (DielsKranz, 1959-1960:B Fr.4). When a moving body is every moment of its "movement" at one specific place, it is after all at rest, since "being in one place" simply means "not being in motion". It is not of any help, as Descartes has tried to do, to define movement in terms of change of place (The Principles of Philosophy, Part II, IV - we shall return to this view in connection with immanent criticism and the difference between an antinomny and a logical contradiction).

One of the two substances distinguished by Descartes is characterized by the essential feature of extension. However, in one sense the extension of a body is nothing but its place. But if extension, i.e. its place, is the very essence of a body (cf. Med II), then the definition of movement as a change of place is antinomic: being essentrally its place, no body could ever change place - at least not without simultaneously abolishing its very essence!

Let us consider another example, that of historicism. According to historicism everything (law, morality, art, faith, language and so on) is taken up in the flow of historical change and is everywhere only comprehensible as elements of a historical process. Contrary to this claim we are used to speak about legal history, art history, economic history, and so on. But if law, art and economics are nothing but history, we in fact must deal with the contradiction of a historical history. Whatever is history, cannot have a history, and whatever has a history, cannot itself be history. The irony is that historicism, reducing every facet of reality to the historical mode, has thus eliminated the very meaning of history - if everything is history, there is nothing that can have a history!

Thus far we have emphasized the irreducibility of primitive terms residing in the different universal modalities or aspects of reality. Of course they also display a remarkable coherence. To account for these inter-relationships, we provisionally 
have to overlook other differences between the natural aspects (number, space, movement, the physical, biotical and sensitive aspects) and the aspects typical of human activities (the logical, historical, sign-mode, social, economic, aesthetic, juridical, ethical and certitudinal aspects). Let us provisionally call these interrelationships "moments-of-coherence".

Dependent on the specific place of an aspect, one may detect a number of "moments-of-coherence" within its structure. In a certain sense one can say that through its "moments-of-coherence", a specific aspect reflects its coherence with all other aspects of reality. Consider the following inter-relations within the structure of the social aspect: social unity and multiplicity (relation with the numerical aspect); social sphere, coherence and stratification (relation with the spatial aspect); social endurance (relation with the kinematic aspect); social dynamics (relation with the physical aspect); social growth, differentiation and integration (relation with the biotic aspect); social sensitivity (relation with the emotional aspect); social concensus and conflict (relation with the logical aspect); social power (relation with the cultural aspect); social meaning, expression and interpretation (relation with the sign-aspect); social style (relation with the aesthetic aspect); social justice (relation with the juridical aspect); social integrity (relation with the ethical aspect); and social security or certainty (relation with the certitudinal aspect).

This representation might give the impression of a static scheme. However, the analysis of any inter-relationship is at once also a dynamic concern which constantly refers to other (not yet analyzed) "moments-of-coherence". Consider for example the concept social order. This concept implies a unity in the multiplicity of social norms that constitute a specific social order. To attain such a unity, the relevant office-bearer, as the competent organ, should constantly take care that, within his sphere of competence, the necessary reformational changes take place in order to ensure the internal stability and solidarity of the life-form concerned, amidst whatever external changes that might occur.

From this brief discussion it should be clear that the problem of the coherence of irreducibles not only pertains to the core of philosophy, but simultaneously confronts the various special sciences with inescapable philosophical basic problems.

We now proceed to an analysis of the structure of analysis and the implied logical principles.

\section{Epistemic values and the nature of analysis}

Analysis comprises both an act of identification and an act of distinguishing. In Greek philosophy it was realized that these acts of identification and dis- 
tinguishing are subject to the logical principles of identity and non-contradiction. Already Aristotle framed the principle of the excluded middle (Metaph.1057a33) which claims that any statement is either true or false.

Since the rise of the Baden School of neo-Kantian thought (Windelband/Rickert) the philosophical legacy of the West has become accustomed to speak about values instead of principles (or: norms). In particular, the application of rules is distinguished from evaluating (cf. Kuhn, 1977:331; Kuhn, 1984:379). Acknowledging that they are not exhaustive, Kuhn (1984:373) mentions the following five values influencing theory choice: "accuracy, consistency, scope, simplicity, and fruitfulness". In his discussion of epistemic values, McMullin (1983:11) follows Kuhn and also discusses the choice of a theory in terms of value-judgements which differ from the mere application of a rule. He preferably speaks about "epistemic values" and transforms the values mentioned by Kuhn by referring to them as "predictive accuracy, internal coherence, external consistency, unifying power and epistemic fertility". To this list epistemic simplicity is added (McMullin, 1983:15-16).

It is clear that this way of dealing with "epistemic values" is dependent on underlying coherences between the analytical facet of theory formation and diverse non-analytic aspects of our experience. For example, "fertility" first of all reminds us of a biotic phenomenon. 2 Plants need "fertile soil" in order to grow properly and bear fruits. Analogously, theories may turn out to be "fruitful" by bearing "fruits". We may refer to this state of affairs by saying that we encounter, in the value of epistemic fertility, a biotical analogy (a biotical "moment-ofcoherence") within the structure of theoretical thought, i.e. within the structure of (deepened) analysis.

Similarly, we may relate consistency to the logical principle of non-contradiction, which analogously reflect the meaning of being distinct, i.e. of the arithmetical meaning of a discrete quantity. Number shows its nuclear meaning by way of being a (distinct) multiplicity - first of all evinced in the succession of natural numbers. Although logicism tries to deny the original arithmetical meaning of quantity by attempting to reduce it to a supposedly logical concept of classes, it does not escape from a petitio principii. Russell (1956:119) explains his logicistic aim in terms of his attempted logical "definition" of the number 2 :

$1+1$ is the number of a class $w$ which is the logical sum of two classes $u$ and $v$ which have no common term and have each only one term. The chief point to

2 I am using the unfamiliar term biotic in stead of biological. Strictly speaking, bio-logy is the scientific study of biotic phenomena. Similar abuses of this suffix is found in terms like psychological (in stead of psychical), socio-logical (in stead of social), and onto-logical (in stead of ontical). 
be observed is, that logical addition of numbers is the fundamental notion, while arithmetical addition of numbers is wholly subsequent.

We only have to consider his words "two classes $u$ and $v$ " to realize the circularity: where does he get hold of the notion "two"? 3 He simply uses the number " 2 " in its original arithmetical meaning of quantity in order to distinguish the two classes $u$ and $v$ from each other to start with, and then wants to deduce it again from an act of "logical addition". If our notion of unity and multiplicity first of all relates to arithmetical phenomena, then it is clear that the meaning of the logical principle of identity and non-contradiction as such analogically reflects this basic arithmetical meaning. Whatever is given as a discrete unity (as being distinct) is identical to itself (the basis of the principle of identity) and is different from whatever it is not (the basis of the principle of non-contradiction)

\section{The twofold nature of an analogy}

The notion of an analogy contains two elements: similarity and difference - and these elements are closely connected with the nature of analysis as identifying and distinguishing. To be sure, one can only identify and distinguish on the basis both of similarities and differences. When we differentiate between life in a biotic sense and social life, we are simultaneously confronted with a moment of similarity: the term life, and with a difference: the difference between the "biotical" and the "social". Surely, life in a biotic sense fundamentally differs from life in a social sense. Therefore, in this moment of similarity the difference between the social aspect and the biotic aspect reveals itself. It sounds almost paradoxical to say that two aspects show a similarity precisely in that moment which reveals the difference between them.

This kind of a "difference in terms of similarity" may be called a (modal) analogy. 5 Surely, modal analogies are not the only kind of analogies which one

3 Already in 1910 Cassirer criticized this circularity (see Cassirer, 1969:67-68) "Die Bestimmung der Zahl durch die Aequivalenz von Klassen setzt voraus, dass diese Klassen selbst als eine Mehrheit gegeben sind" ("The determination of number by means of the equivalence of classes presupposes that these classes themselves are given as a multiplicity"). In connection with the similarity between classes Cassirer (1969:68) proceeds: "But even if we, according to this perspective, beforehand could have left aside the attempt numerically to differentiate the classes we are comparing with each other, then it is still presupposed that we have opposed the classes as wholes, and precisely by doing that should have conceived them as 'two' distinct (classes)".

4 Singh (1985:76) also points out that Russell's attempt makes him a victim of the "vicious circle principle".

5 The term "modal" indicates the various "modes of experience", i.e. the different functional ways in which we are able to experience reality. Traditionally this dimension of reality is related to 
can distinguish, since entities also evince differences in their moments of similarity. Our lingual ability to designate these entitary analogies, as distinct from modal analogies, is known to us in the form of metaphors (viz. "foot of the mountain"). ${ }^{6}$

In order to analyze the nature of logical principles we have to focus our attention on the modal analogies at the law-side of the logical aspect. As a guideline we now have the following two modal analogies: the logical principles of identity and non-contradiction (arithmetical analogies within the modal structure of analysis) and the mentioned value of epistemic fertility (representing a biotical analogy within the modal structure of analysis). From this perspective there is no ground to differentiate between these two values/principles in so far as they both display the same ontical structure - they are examples of an inter-modal coherence between different modal aspects of reality.

An important part of the philosophy of Dooyeweerd is dedicated to an analysis of the inter-modal coherence between the different aspects of reality. Although he does not relate the principles of identity and non-contradiction to the arithmetical analogy present in identifying and distingushing, he does explain the principium rationis sufficientis (thus named by Leibniz) in terms of the physical analogy within the modal structure of the analytical aspect (Dooyeweerd, 1996 II:119). ${ }^{7}$ Already in 1813 Schopenhauer explained the nature of this logical principle as follows:

As such it asserts that, if a judgment is to express a piece of knowledge, it must have a sufficient ground or reason (Grund); by virtue of this quality, it then receives the predicate true. Truth is therefore the reference of a judgment to something different therefrom. This something is called the ground or reason of the judgment ... (see Schopenhauer, 1974:156).

properties which are different from entities ("substances"). Being alive and being social are two functional properties of human beings. Consequently we can also call modal analogies "property analogies"

6 In passing we note that a metaphor demonstrates two important things: (a) the difference between the logical mode and the sign-mode (or: the difference between concept and word), and (b) the foundational role of the logical mode in relation to the sign-mode. Simply think about the well-known example of a "boxing ring". If the sign-mode of reality coincides with the logical mode, $\mathrm{i} e$ if it is not distinct from the logical mode, then this metaphor would be an assertion that a "square circle" exists! (Cassirer [1969:16] refers to this well-known example of an illogical concept - stemming from Russell - in an inverted form: a "round quadrangle" ["rundes Viereck'].)

7 Stafleu (1987:31) gives a related description of the nature of scientific prediction and explanation. 
We want to designate all analogies from other modal aspects revealing themselves within the logical-analytical mode in this way as modal logical principles. Only when these principles are given a positive form, i.e. when they are "positivized", do we meet logical rules that could be applied, such as in the case of the logical rules of classical Aristotelian predicate logic or those of modern symbolic logic (compare Copi, 1994 II:206-450).

The distinction between modal logical norms/principles/values and their concretization/positivization rests on the distinction between the determining and delimiting norm-side of the logical aspect and that which is correlatively factually subjected to this determining norm-side. Concepts, statements and arguments are factually subjected to the logical principles/norms. Only when we acknowledge this distinction is it possible to differentiate between logically correct concept formation, statements and arguments and illogical concept formation, statements and arguments.

The inter-relations at stake are sometimes extremely subtle and complicated. Assessing the status of the principle of the excluded middle would amply illustrate this claim.

\section{The universal applicability of the principle of the excluded middle in question}

It is known that Brouwer rejects the universal applicability of the principle of the excluded middle (partly) because his neo-intuitionistic mathematics identifies mathematical existence completely with what could be constructed. For this reason Brouwer $(1919 \mathrm{a} 9)$ states that the issue concerning the validity of the principle of the excluded middle is equivalent to the question concerning the possibility of solving mathematical problems (1919a:9). He says that whether, in the decimal expansion of $\pi$, infinitely many combinations of equal successive digits appear, must be viewed as uncertain. Heyting specifically uses examples concerning the occurrence of the sequence 0123456789 in the decimal expansion of $\pi$. Write down, for instance, the decimal expansion of $\pi$ :

$$
\pi=3.1415
$$

and the decimal fraction

$\rho=0.3333 \ldots$

which breaks off as soon as the sequence 0123456789 occurs in the decimal expansion of $\pi{ }^{8}$ By accepting the principle of the excluded 
middle, the following must be correct:

$\rho=1 / 3$ or $\rho \neq 1 / 3$

According to the logic of intuitionism, the expression "U v (-U)" implies that we must be able to construct a proof for every mathematical statement $\mathrm{U}$, or construct, by starting with the assumption that $U$ is valid, a contradiction. But then, the same requirements must apply to the above-mentioned case. That is, however, impossible, for to prove one of the statements $\rho=1 / 3$ or $\rho \neq 1 / 3$, we must first of all be able to decide if the sequence 0123456789 does occur in the decimal expansion of $\pi$. Since our present state of mathematical knowledge does not allow this, intuitionism rejects the universal scope of the principle of the excluded middle - whenever the infinite is at stake it is inapplicable.

With his arguments Brouwer convinced Ludwig Wittgenstein and Hermann Weyl. Wittgenstein (1968) explains his stance in terms of a similar example. It seems self-evident that the sequence 7777 either occurs somewhere in the decimal expansion of $\pi$, or it does not:

We want, that is, to quote the law of the excluded middle and to say: 'Either such an image is in his mind, or it is not; there is no third possibility!' - We encounter this queer argument also in other regions of philosophy. 'In the decimal expansion of $\pi$ either the group 7777 occurs, or it does not - there is no third possibility'. That is to say 'God sees - but we don't know'. But what does that mean? - We use a picture; the picture of a visible series which one person sees the whole of and another not. The law of the excluded middle says here: It must either look like this, or like that. So it really - and this is a truism - says nothing at all, but gives us a picture (Wittgenstein, 1968:112, par. 352; cp. p. 127 , par. 426 .)

These examples are dependent on an underlying divergence which stand in relation to the opposing evaluation of the nature of the infinite by intuitionism and the other trends in modern mathematics.

Traditionally a distinction is drawn between the potential infinite $(P I)$ and the actual infinite $(A D)$. With reference to Aristotle (cf. Phys. 208a6), Cantor

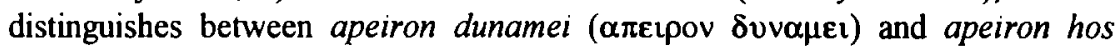
aforisménon ( $\alpha \pi \varepsilon i \rho o v$ os $\alpha \varphi \omega \rho \imath \sigma \mu \varepsilon v o v$ ) (the $P I$ and the $A I$ ). Cantors general description (1962:401) is:

We preferably refer to the $P I$ where we encounter an undetermined varying finite magnitude that either increases beyond all finite limits ... or decreases beneath all finite limits of smallness ...; generally I always speak of $P I$ when we consider an undetermined magnitude which allows for a numberless 


\section{Ontological considerations in the study of Loglc}

multiplicity of determinations. ${ }^{9}$... The $A I$, on the other hand, is to be seen as a quantity (Quantum) which is not varying, since it is firm and determined in all its parts, a genuine constant, although at the same time it surpasses every similar finite magnitude in size.

Cantor (1962:404) also refers to the $P I$ as the "uneigentliches Unendliches" ("improper infinite"), since its reality is dependent on the $A I$ which alone makes it possible.

In radical opposition to Cantor's employment of the $A I$, Weyl (1946:9) supports Brouwer's rejection of the $\mathrm{Al}$ :

Brouwer opened our eyes and made us see how far classical mathematics, nourished by a belief in the 'absolute' that transcends all human possibilities of realization, goes beyond such statements as can claim real meaning and truth founded on evidence.

\section{The whole-part relation}

The relevance of the distinction between the $P I$ and $A I$ for the principle of the excluded middle is first of all seen in relation to the notion of a totality or a whole. Cantor (1962:401) speaks about a "Quantum" which is "firm and determined in all its parts", thus implying the nature of a whole or totality. When "all the parts" are present, a whole is totally given (cf. Foradori, 1933) - and only when we have a whole is it possible to execute a division entailing an either/or. Clearly, therefore, if an infinite totality (the $A I$ ) is rejected by intuitionism, then also the applicability of the principle of the excluded middle in the case of the infinite cannot be upheld.10

Whereas it is not difficult to locate the most primitive meaning of infinity as belonging to our arithmetical intuition of one, another one, and so on without an end, i.e. endlessly, infinitely, ${ }^{11}$ it is not so clear why we have to distinguish this

9 Note that Cantor still uses the notion of a magnitude (a term with a geometrical descent), instead of (numerical) value

10 Intuitionism prefers not to speak about a set in the traditional sense of the word. When a common mode of generation for its elements is defined it introduces the notion of a spread, and when a characteristic property of its elements is meant the term species is used (Heyting, 1971:36). Of course, according to intuitionism, the law of the excluded middle does hold in the case of finte totalities.

11 In his chapter dealing with the "arithmetization of mathematics", Voss $(1913: 33)$ refers to Husserl and Wundt in connection with the psychological notion of successive thought acts. It was W.R. Hamilton who, in a typical Kantian fashion, defined algebra as the "science of pure time" (1833). We shall argue below that the notion of time has a place in mathematics without understanding it in a psychological sense. 
primitive meaning of infinity (i.e. endlessness) from the meaning of the actual infinite.

Is there no logical continuity between the acceptance of an endless sequence and the nature of the actual infinity of this sequence?

Those committed merely to the acknowledgement of the potential infinite do not allow for any fashion of presenting the multiplicity of elements of such an endless sequence as being given at once, without any succession. Kaufmann (1968:144), for example, explicitly speaks about the unfounded supposition of "the actual infinite as a totality of discrete elements".

At this stage it must be clear that our problem now concerns the question whether it is possible to reduce the notion of a totality (whole) to the quantitative meaning of number. The relation of a whole (totality) to its parts was already discovered in early Greek philosophy - partially as a result from the discovery of incommensurability by the Pythagorean thinker Hippasos of Metapontum (cf. Von Fritz, 1965). The subsequent Eleatic school characterizes their new metaphysics of being in terms derived from our intuition of space - embedded in a fundamental geomatrization of Greek mathematics. Zeno's B Fragment 3 at once looks at the two sides of the whole-parts relation. The movement from the parts to the whole yields a finite number of parts adding up to the whole. The opposite direction entails the endless divisibility of a whole which implies that in this case the number of the parts is infinite. This perspective can also be used in support of the interpretation given to Zeno's B Fragment 1 by Hasse and Scholz (1928:10-13). This first Fragment (which we inherited from Simplicius) states that if a multiplicity exists, then simultaneously it must be large and small; large up to infinity and small up to nothingness. Scholz and Hasse (1928:11) clarify this fragment by interpreting it as follows:

If it is permissible to conceptualize a line-stretch as an aggregate of infinitely many small line stretches, then there are two and only two possibilities. Every basic line segment either has a finite size (larger than zero), in which case the aggregate of line-stretches transcends every finite line-stretch; or the supposed line-stretches are zero-stretches in the strict sense of the word, in which case the composed line is also a zero-stretch, because the combination of zerostretches can always only produce a zero-stretch, however large the number of zero-stretches used may be.

Besides the fact that we can render the two mentioned fragments of Zeno perfectly intelligible by using the spatial whole-part relation, further support for this understanding may also be drawn from the account which Aristotle gives of Zeno's arguments (cf. Metaph. 233al3 ff. and 239b5 ff.). One of the standard expositions of Zeno's argumentation against the reality of motion is completely dependent on the employment of the spatial whole-part relation with its implied 


\section{Ontological considerations in the study of Logic}

trait of infinite divisibility. Guthrie (1980:91-92) explains this argument by saying that according to Zeno

[m]otion is impossible because an object moving between any two points $A$ and B must always cover half the distance before it gets to the end. But before covering half the distance it must cover half of the half, and so on ad infinitum Thus to traverse any distance at all it must cover an infinite number of points, which is impossible in any finite time.

This spatial orientation explains why subsequent Greek thinkers explored still further the spatial whole-part relation. Anaxagoras claims that we are not entitled to speak about the smallest, since there always exists something smaller. That what is can never cease to be through continued division, no matter how far this process of division is carried through (B Fragment 3 ). And since no smallest can exist, it is impossible (for any part) to be separated and set on its own, because it must now as in the beginning, exist together with everything else (B Fragment 6). This "existence together/coherent existence" refers to the coherence of spatial continuity in which all (material) things are fitted. However, this continuity is not composed out of discrete (separated) parts, as if they were cut apart by an axe (B Fragment 8).

\section{Irreducibility of the totality-character of continuity}

With these distinctions Anaxagoras not only anticipates the view of Aristotle, since he also provides modern intuitionistic mathematics with valuable insights. Weyl (1931:1) is most explicit about this heritage: "Yes, especially now, in the foundations of mathematics, we are everywhere invited immediately to go back to the Greeks"12. When he discusses the "present" state of mathematical knowledge in 1926 he (Weyl, 1926:1-2) starts with Anaxagoras. He often characterizes continuity in terms of the whole-part relation (cf. Weyl, 1921:77, and 1966:74).

Intuitionistic mathematics here also follows fundamental insights from Aristotle. Although Aristotle analyzed both space and number within the perspective of one category, namely that of quantity (number is a discrete quantity and space is a continuous quantity), he nonetheless develops a remarkable insight into the structure of spatial continuity. The parts of a discrete quantity possess no common boundary, whereas, in the case of a line (as a continuous quantity) it is always possible to detect a common limit of its parts (Categoriae, $4 \mathrm{~b} 25 \mathrm{ff}$, , 5al ff.): "The act in which a continuous distance is divided into two halves takes one point twice since it is viewed as starting-point and end-point" (Physica, 263a23

12 "Ja gerade heute sehen wir uns genötigt, überall in den Grundlagen der Mathematik wieder unmittelbar auf den Griechen zurückzugehen" (Weyl, 1931:1). 
ff.). 13 According to Aristotle it is therefore self-evident that "everything continuous is divisible into divisible parts which are infinitely divisible" (Physica, $231 \mathrm{bl}$ g ff.).

It is especially this trait of continuity that is taken seriously in intuitionistic mathematics. Weyl (1921:77) points out: "That it has parts, is a basic property of the continuum", and adds: " it belongs to the very essence of the continuum that every one of its parts admits a limitless divisibility".

According to Weyl (1921:77), the general aim of Weierstrass, Dedekind and Cantor, namely to arithmetize spatial continuity completely, had to take recourse to the neighbourhood concept: "To account for the continuous coherence of the points, contemporary analysis, which has separated the continuum into a set of isolated points, takes refuge to the neighbourhood concept".

However, it is not at all imperative to adhere to the intuitionistic approach in modern mathematics in order to realize that the totality-character of continuity is irreducible to numerical notions. Bernays (1976:74) did sense the irreducibility of the spatial whole-part relation (the totality-property of spatial continuity) with an astonishing lucidity: "The property of being a totality "undeniably belongs to the geometric idea of the continuum. And it is this characteristic which resists a complete arithmetization of the continuum' ${ }^{14}$

In another context he even states that the classical foundation of the real numbers given by Cantor and Dedekind does not "manifest a complete arithmetization" (Bemays, 1976:187-188). To this he adds the remark: "It is in any case doubtful whether a complete arithmetization of the idea of the continuum could be justified. The idea of the continuum is any way originally a geometrical idea" (Bernays, 1976:188). His deeply felt reaction against the mistaken and one-sided nature of modern arithmeticism is best seen from his following remark:

The arithmetizing monism in mathematics is an arbitrary thesis. The claim that the field of investigation of mathematics purely emerges from the representation of number is not at all shown. Much rather, it is presumably the case that concepts such as a continuous curve and an area, and in particular the concepts used in topology, are not reducible to notions of number (Zahlvorstellungen)" (Bernays, 1976:188).

13 Cf. Foradori (1933:162, 166). Böhme (1966:308 ff.) highlights the striking similarities between the Aristotelian conception of the continuum and the Cantor-Dedekind characterization thereof. He shows that although the latter employs the actual infinite - totally rejected by Aristotle they still conform to the two criteria which Aristotle developed for continuity.

14 "Und es ist auch dieser Charakter, der einer vollkommenen Arithmetisienung des Kontinuums entgegensteht" - Bernays, 1976:74 


\section{A crucial inter-modal coherence}

Anothor way to phrase these considerations is to say that the fundamental difference between the potential infinite and the actual infinite stands and falls with the difference between the primitive meaning of an arithmetical succession (preferably designated as the successive infinite), and the totality-character of an actual infinite set (where all the elements are viewed as being present simultaneously). In the latter case it is preferable to speak about the at once infinite. ${ }^{15}$

It is also clear from Cantor's notion of a set that he explicitly uses the feature of being a totality to characterize it: "We understand a 'set' to be any collection into a whole $\mathrm{M}$ of definite and distinct objects $\mathrm{m}$ of our intuition or our thought (which are called the 'elements' of M [Cantor, 1962:282])" 16 Since the notion of a set and that of an element are indefinable terms in Zermelo-Fraenkel set theory, the formulation of the "Axiom of Infinity" gives the impression that only the successive infinite is intended (cf. Fraenkel et al., 1973:46). In particular, when the "Axiom of Infinity" is read in coherence with the "Axiom of Power-Set" (cf. Fraenkel et al., 1973:35), it is clear that together they (also) cover the case of infinite totalities (where all the subsets of an infinite set also constitute a new set). ${ }^{17}$

It must be clear that our argument does not introduce continuity in its irreducible spatial sense into the meaning of number. Much rather, we here need the abovementioned figure of a modal analogy: any arithmetical succession may, under the guidance of our spatial intuition of simultaneity, be viewed as if all its elements are present at once - in which case we have employed the regulative idea of the at once infinite, accounted for in terms of an anticipatory analogy of space within the meaning of number.

I5 These terms were already used in the disputes of the early 14th century about the infinity of God. Compare the expressions infinitum successivum and infinitum simultaneum (Maier, 1964:77-79)

16 "Unter einer 'Menge' verstehen wir jede Zusammenfassung $M$ von bestimmten wohlunterschiedenen Objekten $\mathrm{m}$ unserer Anschauung oder unseres Denkens (welche die 'Elemente' von M genannt werden) zu einem Ganzen" (Cantor, 1962:282). In his description of the nature of "Teilmengen" ("subsets") on the same page, the word "at once" ("zugleich") is used constitutively. A good discussion of Cantor's concept of a set is found in Singh (1985)

17 We note in passing that it was the postulation of an infinite 'class' which showed the untenability of Russell's logicistic project. In 1919 he had to admit that all of his earlier proofs for the existence of an infinite class are invalid (1919:134-135; cf. Morris, 1929:456). Fraenkel et al. (1973:186), remark: "It seems, then, that the only really serious drawback in the Frege-Russell thesis is the doubtful status of InfAx, according to the interpretation intended by them". 
In other words, the use of the at once infinite (with its irreducibility to the successive infinite) stands and falls with the irreducibility of the spatial time-order of simultaneity which is simply the determining order for any coherent totality, since to constitute any spatial whole all the parts have to be present at once.

\section{Remark:}

Also in the aspects of number and space we have to distinguish between a law-side and a factual side. The former plays a limiting and determining role, whereas the latter is limited and determined by the order at the lawside. The history of time-measurement suggests that time should be seen as a unique dimension of reality which cannot be identified with the physical aspect of reality. First of all time-measurement used the numerical timeorder of succession - by counting the days, the weeks, months and years. Then they used the spatial time-order of simultaneity - with the aid of instruments like sundials. Subsequently, the kinematical order of constancy was used (cp. the regular swing of a pendulum in a mechanical clockwork). Finally, in our century, we are using the irreversible physical timeorder - for example in atomic clocks and in the procedure used to determine the age of the different earth layers. This perspective continues insights of Descartes - cf. his notion of numeros, ordo and duratio (cf. Becker, 1973:269) - and Kant - cf. his three modes of time namely succession, co-existence and duration (Kant, 1956.B-219). The acknowledgement of time as a unique dimension of reality is also worked out by Stafleu in his analysis of the foundations of physics (cf. Stafleu, 1980:16, $83 \mathrm{ff}$.).

In the development of Greek philosophy and mathematics it was conjectured to view our intuition of space as being more basic than that of number. Fraenkel $e t$ al. (1973:213) remark:

Certainly the discrete admits an easier access to logical analysis, and the tendency of arithmetization, already underlying Zeno's paradoxes, has been impressing its mark upon modern mathematics and may be perceived in axiomatics of set theory as well as in metamathematics. However, the converse direction is also conceivable, for intuition seems to comprehend the continuum at once (my italics - DFMS); mainly for this reason Greek mathematics and philosophy were inclined to consider continuity to be the simpler concept and to contemplate combinatorial concepts and facts from an analytic view.

Although we want to acknowledge the spatial descent of the notion of a whole and its parts, ${ }^{18}$ it must also be clear that the meaning of spatial continuity

18 In the light of this perspective the following remark of Bemays is quite understandable: "The idea of the continuum is a geometrical idea which is expressed by analysis in terms of arithmetic" ("Die ldee des Kontinuums ist eine geometrische Idee, welche durch die Analysis in 
presupposes that of number. Consequently, where the infinite divisibility of any spatial continuum refers back (retrocipates) to the primitive meaning of the successive infinite, the at once infinite refers forward (i.e. anticipates) to the spatial order of simultaneity with its factual correlate, the totality-character implied and determined by this order of at once.

\section{The principle of the excluded middle: a retrocipation to an anticipation}

Against the foregoing background we may now formulate the ontical status of the principle of the excluded middle. As such it is first of all a part of the arithmetical analogy within the modal structure of the logical-analytical mode, intimately connected with the principles of identity and non-contradiction. To be sure, in the finite case, the bifurcation of $A$ and non-A clearly excludes any third possibility.

However, in order to ensure the universal applicability of this logical principle, i.e. also in the case of the infinite, we have to acknowledge the (irreducible) meaning of the at once infinite, which itself is completely dependent on the irreducibility of the spatial order of simultaneity with its implied correlate: the whole-part relation.

Only under the anticipatory guidance of the regulative hypothesis of the at once infinite are we justified in accepting that the principle of the excluded middle holds in the infinite case as well. In a striking way Hermann Weyl supports our claim by alluding to the at once infinite in connection with the claim that a number with a property $P$ exists or that all numbers implicitly have the opposite property non- $P$ : "The principle of the excluded middle for such sentences may be valid for God who surveys the infinite sequence of natural numbers, as it were, with one glance, but not for human logic" (Weyl, 1951:552).

Therefore, via the (retrocipatory) analogy of number within the structure of analysis, this principle finds its ultimate foundation in the numerical anticipation to the meaning of space, which entitle us to say that the ontical status of the

arithmetischer Sprache ausgedrükt wird") Further on this page, in connection with shortcomings in the intuitionistic conception, he adds (Bernays, 1976:74) that it is preciscly this totality-feature of the continuum which resists arithmetization: "This stems from the fact that on the intuitionistic conception, the continuum does not have the character of a totality, which undeniably belongs to the geometrical idea of the continuum. And it is this characteristic of the continuum which would resist perfect arithmetization" ("Das rührt davon her, dass die intuitionistische Vorstellung nicht jenen Charakter der Geschlossenheit bezitzt, der zweifellos zur geometrischen Vorstellung des Kontinuums gehört. Und es ist auch dieser Charakter, der einer vollkommenen Arithmetisierung des Kontinuums entgegensteht" - Bernays, 1976:74). 
principle of the excluded middle is given in its being a retrocipation to an anticipation!

In other words, the meaning of the principle of the excluded middle is given in a retrocipation from the logical-analytical mode to the arithmetical mode, which in turn anticipates the factual spatial whole-part relation as subjected to and as determined by the spatial time-order of simultaneity.

We can expand our ontological considerations in order to account for another important distinction, namely that between contradiction and antinomy.

\section{Contradiction and antinomy}

The two "legs" of analysis, namely identification and distinguishing, analogically reflect the meaning of number within the structure of the logical aspect - it presupposes the presence of a logical multiplicity and unity. The numerical succession of one, another one, and so on makes it possible to identify any moment in this succession and to distinguish it from any other one. In general one can say that logical contradictions are always confined to an intra-modal opposition - for instance when two spatial figures are incorrectly distinguished in the illogical (i.e., logically contradictory) reference to a "square circle". These two figures, namely a square and a circle, are enclosed within the modal structure of the spatial aspect. However, when Zeno tried to reduce the meaning of movement to that of statical positions in space, two different aspects are confused, i.e., then an inter-modal opposition, designated as an antinomy, is given.

It should be noted that such an inter-modal antinomy always implies a logical contradiction (which is intra-modal), but not vice versa. Descartes' "definition" (i.e. reduction!) of movement as a "change of place" implies the following logical contradiction: if a body is its place, and if movement is a change of place, then a body can only move if it changes "essentially" - implying that it cannot move (or, succintly: a body can move if and only if it cannot move). ${ }^{19}$

\section{Once again the principle of sufficient reason (principium rationis sufficientis)}

We have seen that this principle finds its ontical basis in the physical (causal) analogy at the law-side of the logical aspect. Whereas the principles of identity, (non-)contradiction and the excluded middle operate within the confines of logic

19 This distinction between antinomy and contradiction was overlooked in Hart's work Understanding Our World (1984, cf. p. 132, 133) 


\section{Ontological considerations in the study of Logic}

the principle of sufficient reason refers one beyond logic to the grounds (reasons) brought forward in support of specific conclusions.

This principle, originally formulated by Leibniz, was subjected to an extensive investigation by A. Schopenhauer in 1813. He called it the principle of sufficient ground of knowledge (principium rationis sufficientis cognoscendi)

As such it asserts that, if a judgement is to express a piece of knowledge, it must have sufficient ground or reason (Grund); by virtue of this quality, it then receives the predicate true. Truth is therefore the reference of a judgement to something different therefrom. This something is called the ground or reason of the judgement ... (Schopenhauer, 1974:156).

Within the context of scholarly interaction all the mentioned logical principles play an essential role. Students entering (university) colleges are normally told that they should develop a critical mind, that they should not merely accept what is told to them by their teachers or text books. I want to reverse this maxim before you can critique someone it is required what you consider praiseworthy in the thought of a scholar (philosopher or special scientist), thus first of all showing solidarity with that person, criticism is inadequate. The maxim is not to be critical, but to show a sense of critical solidarity! Vitalism did see something in reality worth of being acknowledged: the fact that our experiential world does include a biotical aspect. However, due to its over-emphasizing of this aspect, the very meaning of what was legitimately seen is distorted. The principle of critical solidarity requires that it is inadmissible to criticize a scholar before a positive assessment is given of the fruitful insights this scholar advanced.

The crucial question now is: How do we side-step the "dead end" of ultimately merely positing our own alternative over against the view-point of someone else, without making any intrinsic "thought-contact"?

\section{Factual and immanent criticism}

When a particular theoretical approach to reality cannot do justice to undeniable "states of affairs", one can confront it with the relevant data - thus exercizing factual criticism. The dualistic anthropology of St. Thomas Aquinas, for example, believed that the human intellect ("mind") could operate quite independent from any activity of the "body". From what we today know about the substructures of human functioning, this dualism lacks any factual support. Every thought activity is dependent upon certain functions within the human brain, which, via the biotic substructure, ultimately pre-supposes a physico-chemical substratum. ${ }^{20}$ 
Especially in scientific and scholarly interaction, another form of criticism is of fundamental importance: immanent critique.

This method could make use of all known valid forms of logical inference - as long as the outcome is that the position criticized was found guilty of contradicting itself internally. Immanent criticism must try to clarify the question whether the unveiled contradictions are evidence of an underlying antinomy.

Consider for example they way in which Descartes wanted to demonstrate that God exists. ${ }^{21} \mathrm{He}$ argues that the idea of God as an infinite substance must, due to my finiteness, be caused by God himself (Med. III). This infinity of God is known (intelligi), not as a negation, but as a richer reality, in spite of the fact that we cannot comprehend (comprehendl) it. Descartes believes that in a clare et distincte manner he thus proved the existence of God, since whatever is clearly and distinctly conceived is true. The circularity (petitio principii) of this reasoning is seen as soon as we ask: what or who ensure the truth of clear and distinct understanding? To this question Descartes answers: God, since he cannot deceive us (Med. IV). Thus, to clearly and distinctly prove the existence of God, Descartes had to start from the assumption that God exists as the guarantee of clear and distinct reasoning!

A similar form of immanent criticism is uncovered by considering the idea that matter should be seen as the principium individuationis (principle of individuation): everything numerous possesses matter (Aristotle, Metaphysica 1074). St. Thomas Aquinas followed Aristotle but encountered serious difficulties. This view, as such, did not imply immediate problems for Aristotle's anthropology, since he considered only the combination of form (soul) and matter (body) to constitute a substantial unity. St. Thomas, on the other hand, being influenced by the Platonic "proofs" concerning the indestructibility of the "soul", wanted to safe-guard a separate (immaterial) existence for the soul as a substance, taken in full separation from the material body. By implication then, there must be a multiplicity of souls without any matter - contradicting the mentioned Aristotelian claim that everything numerous possesses matter!

Nominalism demonstrates the fate of self-contradiction at a very basic level. It is convinced that outside the human mind there is no universality - only strictly individual things exist in reality. However, in flat contradiction with this conviction, at least one universal trait is implicitly affirmed with regard to the multipicity of individual entities outside the human mind: their being-individual!

21 The impasse of historicism, mentioned above, as well as the argument of Zeno against multiplicity and movement (Achilles and the tortoise) are examples of antinomies which are used in the immanent criticism of these positions. 
In the case of an extreme materialism we find a crucial element of self-reference The basic thesis is given in the statement: everything is matter. If this statement is true, then there must be something immaterial, namely the truth of the claim made! Similarly, the accepted (universal) physical laws are ultimately conditioning material things - but these conditions for the existence of material things are not themselves material.

The ontological considerations that guided our reflection up to this point precludes every attempt to postulate a mutual antagonism between different modes (or their analogies). Von Kibéd (1979) demonstrates this position with an appeal to the (logical) law of identity. His aim is to account for the constancy of an entity - but he does that in terms of a static metaphysics: "The principle of identity, according to which everything is only identical to itself, actually forbids every change, every becoming-different, every stepping-outside of a substance from its being-itself' (Von Kibéd, 1979:59).

He is well aware of the fact that some thinkers (like Aristotle) employed the distinction between essence and appearance to account both for the identity and the change of an entity: "The difficulties accompanying the concept of the changes of an unchangeable thing are side-stepped by dividing the entity into an essential and accidental part, thus producing the possibility to associate unchangeability with its essence and changeability with what is accidental" (Von Kibéd, 1979:60). However, according to Von Kibéd (1979:60 this would not help us, because also the accidental features of an entity are subject to the law of identity: "according to the principle of identity also the accidental must remain identical to itself and cannot abolish its essence, which is given in its accidental nature"). His conclusion is therefore to be expected: "The concept of change is therefore logically unthinkable" (1979:60). What is needed in order to account for change, namely "the concept of causality, is logically seen non-transparent and shows the limits of logical explanation" (1979:60-61). Von Kibéd in fact provides us with a modern version of Zeno's argument against the reality of movement (as change of place).

We conclude our discussion with a few remarks about the mentioned well-known arguments of Zeno against movement and multiplicity. We have stressed the irreducibility of the kinematical aspect in an earlier context. The antinomical implications of Zeno's argument, echoed in Descartes' definition of movement as a change of place, is clearly seen by a communist physicist, H. Hörz. Hörz (1967) explains that classical physics teaches that a moving body finds itself at a specific moment at a specific place. In taking this position, so Horz argues, classical physics precludes an account of the real movement that is at stake. Engels (the colleague and contemporary of Marx) gave a dialectical materialistic account of motion: any moving body is and is not to be located at a specific 
place. Hörz refers to this by speaking about the "dialectical antinomy" (dıalectische Widerspruch) of movement. Explaining the position of Engels in a way that avoids every "logical contradiction", Hörz (1967:11) states: in so far as the body is still moving it is not at a specific place, and in so far as it has arrived at its destination (as a result of its movement) it is at a specific place. Unfortunately Horz continues to see movement as a change of place. He did not realize that the term "place" refers to the primitive meaning of the spatial aspect, whereas the term "change" refers to the primitive meaning of the physical aspect - explaining why it is antinomical to "define" movement as a "change of place"

\section{Literature}

ARISTOTELES $k y k$ ARISTOTLE

ARISTOTLE. The works of Aristotle. Vol. I. Categoriae. Ed. W D Ross Oxford : Oxford University Press. 1937

ARISTOTLE The works of Aristotle Vol. II. Psysica Ed W.D Ross. Oxford : Oxford University Press. 1930

ARISTOTLE. The works of Aristotle. Vol. VIII. Metaphysica Oxford : Clarendon Press. 1948

DESCARTES A discourse of method, meditations and principles Transl John Veitsch. London : Dent. 1965.

BECKER, O., ed. 1965. Zur Geschichte der griechischen Mathematik. Darmstadt Wissenschaftliche Buchgesellschaft.

BECKER, O. 1973 Mathematische Existenz. Untersuchungen zur Logik und Ontologie mathematischer Phanomene. Tubingen Max Niemeyer Verlag

BERNAYS, P. 1976. Abhandlungen zur Philosophie der Mathematik. Darmstadt : Wissenschaftliche Buchgesellschaft

BROUWER, L.E.J. 1919. De onbetrouwbaarheid der logische principes. (In Brouwer, L.E J. Wiskunde, waarheid, werkelijkheid. Groningen Noordhof. p. 5-12.)

CAHN, S.M., KITCHER, P \& SHER, G. 1984 Reason at work. Introductory readings in Philosophy New York : Harcourt Brace Jovanovich Publishers.

CANTOR, G. 1962. [1932]. Gesammelte Abhandlungen mathematischen und philosophischen Inhalts. Hildesheim : George Olms Verlagsbuchhandlung.

CASSIRER, E. 1969. [1910]. Substanzbegriff und Funktionsbegriff. Untersuchungen uber die Grundfragen der Erkenntniskritik. Darmstadt : Wissenschaftliche Buchgesellschaft

COPI, I M. 1994 Introduction to logic. Ninth edition. New York : MacMillan.

DESCARTES. A discourse of method, meditations and principles. Transl. John Veitsch. London: Dent. 1965.

DIELS-KRANZ, H. 1959-1960. Die Fragmente der Vorsokratiker. Vols. I-III. Charlottenburg Weidmannsche Verlagsbuchhandlung.

DOOYEWEERD, H. 1996. A new critique of theoretical thought. (4 Vols.) New edition as part of the collected works of Herman Dooyeweerd, Series A, Volume 2. Lewiston Edwin Mellen Press.

FORADORI, E 1933 Stetigkeit und Kontinuitat als Teilbarkeitseigenschaften. Monatshefte fur Mathematik und Physik, 40:161-180.

FRAENKEL, A.A., BAR-HILLEL, Y, LEVY, A., VAN DALEN, D. 1973. Foundations of set theory. Second revised edition. Amsterdam : North-Holland.

GUTHRIE, W.K.C 1980 [1965] A history of Greek philosophy. Vol. II. (The Presocratic tradition from Parmenides to Democritus.) Cambridge Cambridge University Press 
HAMIIION, W.R. 1833. Theory of conjugate functions, with a preliminary and elementary essay of algebra as the science of pure time. s.l. : s.n.

HART, H. 1984. Understanding our world. An integral ontology. Lanham : University Press of America.

HEYTING, A. 1971. Intuitionism. An introduction. Amsterdam : North-Holland.

HÖZ, H. 1967. Naturforschung und Weltbild. Berlin : s.n.

KANT, I. 1956. Kritik der reinen Vernunft (A-1781/B-1787) Hamburg : Felix Meiner

KAUFMANN, F. 1968. [1930]. Das Unendliche in der Mathematik und seine Ausschaltung Eine Untersuchung uber die Grundlagen der Mathematik. Darmstadt : Wissenschaftliche Buchgeseilschaft.

KUHN, T S. 1977. The essential tension. Chigaco : University of Chicago Press.

KUHN, T.S. 1984 Objectivity, value judgement, and theory choice. (In Cahn, et al. Reason at work. Introductory readings in Philosophy. New York: Harcourt Brace Jovanovich Publishers. p. 371-385.)

MCMULLIN, E. 1983. Values in science. Philosophy of Science Association, 2:3-27

MORRIS, C.W. 1929. Has Russell passed the tortoise! The Journal of Philosophy, 6(17), Aug. 15

MAIER, A. 1964. Diskussion über das Aktuell Unendlichen in der ersten Hälfte des 14 Jahrhunderts. (In Maier, A. Ausgehendes Mittelalter. Vol. I. Rome : s.n.)

RUSSELL, B. 1956. Principles of mathematics. London : Allen \& Unwin

SCHOLZ, H. \& HASSE, H. 1928 Die Grundlagenkrisis der grieschischen Matematik. KantSiudien, 33:37-62.

SCHOPENHAUER, A. 1974. On the fourfold root of the principle of sufficient reason Translated by E.F.J. Payne. Lasalle : s.n.

SCHULZ, G. \& HEITSCH, W. 1967. Philosophische Probleme der Matematik. (In Hörz, H Naturforschung und Weltbild. Berlin : s.n.)

SINGH, D 1985. On Cantor's concept of set. International Logic Review, 32:71-85, Dec.

STAFLEU, M.D. 1980. Time and again. A systematic analysis of the foundation of physics Toronto: VCH/Wedge Publishing Foundation.

STAFLEU, M.D. 1987. Theories at work. On the structure and functioning of theories in science, in particular during the Copernican Revolution. New York : University Press of America.

VON BOHME, G. 1966. Unendlichkeit und Kontinuität. Philosophia Naturalis, 11:304-317

VON FRITZ, K. 1965.[1945] Die Entdeckung der Inkommensurabilitat durch Hippasos von Metapont. (1945.) (In Becker, O., ed. Zur Geschichte der griechischen Mathematik. Darmstadt : Wissenschaftliche Buchgesellschaft.)

VON KIBED, A.V. 1979. Einfuhrung in die Erkenntnislehre. Die Grundrichtungen und die Grenzen der Erkenntnis der Wahrheit. Munchen : Ernst Reinhardt Verlag.

VOSS, A. 1913. Ueber das Wesen der Mathematik. Leipzig : s.n.

WEYL, H. 1926. Die heutige Erkenntnislage in der Mathematik. Erlangen : s.n.

WEYL, H. 1931. Die Stufen des Unendlichen. Jena : s.n.

WEYL, H. 1946. Mathematics and logic. A brief survey serving as a preface to a review of the philosophy of B. Russell. American Mathematical Monthly, 53:2-13.

WEYL, H. 1951. A half-century of mathematics. American Mathematical Monthly, 58:523553.

WEYL, H. 1966. Philosophie der Mathematik und Naturwissenschaft. Third extended ed. Vienna : Oldenbourg.

WITTGENSTEIN, L. 1968. [1953]. Philosophical investigations. Third Edn. Oxford Routledge \& Kegan Paul 